\title{
Prognostic Value of Survivin in Nasopharyngeal Carcinoma: A Systematic Review and Meta-analysis
}

\author{
Wenji Xie*, Ouying Yan*, Feng Liu, Yaqian Han ${ }^{\bowtie}$ and Hui Wang ${ }^{\bowtie}$ \\ Department of Radiotherapy, Hunan Cancer Hospital \& The Affiliated Cancer Hospital of Xiangya School of Medicine, Central South University, 283 Tongzipo \\ Road, Changsha 410013, Hunan, China. \\ *These authors contributed equally to this paper. \\ $\square$ Corresponding authors: Hui Wang, E-mail: wanghui@hnca.org.cn; Yaqian Han, E-mail: hanyaqian@hnca.org.cn.
}

(C) The author(s). This is an open access article distributed under the terms of the Creative Commons Attribution License (https://creativecommons.org/licenses/by/4.0/). See http://ivyspring.com/terms for full terms and conditions.

Received: 2020.03.24; Accepted: 2021.04.26; Published: 2021.05.27

\begin{abstract}
Background: Previous studies have shown that survivin has potential prognostic value in nasopharyngeal carcinoma. However, the results remained controversial until now. Thus, to investigate the influence of survivin expression on prognosis and clinical characteristics in nasopharyngeal carcinoma, we performed this meta-analysis.

Methods: We searched PubMed, PMC, Embase, Web of Science, Cochrane Library, and China National Knowledge Infrastructure electronic databases from their establishment to 1 March 2021. The pooled hazard ratio $(H R)$ and the pooled odds ratio (OR) were used to evaluate the prognostic and clinicopathological values of survivin in nasopharyngeal carcinoma. We used the $\mathrm{I}^{2}$ statistic and the $\mathrm{Q}$ test to evaluate heterogeneity. Meta-regression, publication bias, and sensitivity analyses were also conducted.

Results: A total of 26 eligible studies with 2278 patients were included in our meta-analysis. We found that the expression of survivin is connected with poor overall survival $(H R=1.94 ; 95 \%$ confidence interval $(C l)=1.52-2.48 ; P<0.001)$, lymph node metastasis $(O R=3.01 ; 95 \% C l=2.31-3.91 ; P<0.001)$, local recurrence $(\mathrm{OR}=2.40 ; 95 \% \mathrm{Cl}=1.60-3.61, \mathrm{P}<0.001)$, distant metastasis $(\mathrm{OR}=2.58 ; 95 \% \mathrm{Cl}=1.74-3.84$, $\mathrm{P}<0.001)$, and a higher clinical stage $(\mathrm{OR}=4.58 ; 95 \% \mathrm{Cl}=2.81-7.47, \mathrm{P}<0.001)$. However, no significant correlations were found between survivin expression and radio-sensitivity $(\mathrm{OR}=1.33 ; 95 \% \mathrm{Cl}=0.25-7.17$, $\mathrm{P}=0.737)$ or gender $(\mathrm{OR}=1.02 ; 95 \% \mathrm{Cl}=0.75-1.39, \mathrm{P}=0.887)$.

Conclusions: This meta-analysis indicates that survivin could be used as a biomarker for predicting prognosis in nasopharyngeal carcinoma.
\end{abstract}

Key words: survivin, nasopharyngeal carcinoma, prognosis, meta-analysis

\section{Introduction}

Nasopharyngeal carcinoma (NPC) is a malignancy deriving from the nasopharynx epithelium. Because of its lopsided regional distribution and unique etiological risk factor, NPC has distinct characteristics compared with other head and neck cancer [1]. The incidence of NPC in southeast Asia, norther Africa, and southern China is much higher than that in other areas of world [2]. Moreover, more than $60 \%$ of newly diagnosed NPC patients are in China [3]. Radiotherapy with or without chemotherapy is the mainstay treatment for NPC because of its high radio-sensitivity and special anatomical location [4, 5]. Despite advances in radiotherapy technology and chemotherapy modality, survival outcomes of advanced NPC are still unsatisfactory [6]. Locoregional recurrence and distant metastasis still remain the primary reasons for treatment failure, especially the later [7]. To date, several prognostic indicators, like tumor-nodemetastasis (TNM) stage [8, 9] and Epstein-Barr virus (EBV) DNA [10], have been used to evaluate the survival outcomes of NPC. However, those indicators cannot be accurate enough for predicting the prognosis because of biological heterogeneity and 
false positive rate $[11,12]$. Therefore, a novel and effective biomarker is urgently required to evaluate prognosis for NPC patients.

Survivin, also named baculoviral inhibitor of apoptosis repeat-containing 5 (BIRC5), is an important member of the inhibitors of apoptosis family [13]. Survivin is highly expressed in embryonic tissues and tumors, but rarely expressed in normal adult tissues [14]. It has been reported that survivin plays a key role in the inhibition of apoptosis, tumor cell proliferation, and tumor angiogenesis [15-17]. A number of studies have demonstrated that survivin expression is associated with poor prognosis in various cancers, such as renal cell carcinoma [18], oral squamous cell carcinoma [19], and hepatocellular carcinoma [20].

However, the prognostic and clinicopathological value of survivin expression in patients with NPC remains ambiguity. Therefore, the aim of this metaanalysis is to investigate whether survivin is related to clinicopathological characteristics of NPC and evaluate its prognostic value.

\section{Materials and methods}

\section{Search strategy}

This study was conducted according to the Preferred Reporting Items for Systematic Reviews and Meta-Analyses (PRISMA) criteria [21].

A systematical literature retrieval was conducted without language restriction. We searched PubMed, PMC, Web of Science, Embase, Cochrane Library, and China National Knowledge Infrastructure (CNKI) databases by using the following syntax: ("survivin" or "baculoviral inhibitor of apoptosis repeat-containing 5" or "BIRC5") and ("NPC" or "nasopharyngeal carcinoma" or "nasopharyngeal cancer"). The final search was conducted on Mar 1, 2021. Also, the reference lists of relevant literatures were searched manually for potential eligible studies.

\section{Inclusion and exclusion criteria}

Eligible studies must meet the following inclusion criteria: (a) NPC patients were confirmed by histopathological diagnosis and without other malignances; (b) studies focused on the association between survivin expression and survival outcomes or clinical variables of NPC patients; (c) survivin expression was detected by immunohistochemistry (IHC); (d) sufficient data was provided to extract or estimate hazard ratio (HR) and odds ratio (OR) with 95\% confidence intervals (CIs). The exclusion criteria were as follows: (a) reviews, meta-analysis, letters, comments, case reports and conference abstracts; (b) the study based on cells or animal models; (c) the study failed to provide sufficient data for acquiring
HR, OR and 95\% CI. Two independent investigators assessed the selected studies.

\section{Data extraction and quality assessment}

Data was extracted independently by two investigators. The following required data was retrieved from each included study: last name of first author, year of publication, sample size of the study, country of patients, follow-up duration, data of clinical characteristics (age, gender, stage, radiosensitivity, lymph node metastasis, distant metastasis, and local recurrence), HR and its 95\% CI for survival, Kaplan-Meier curves for survival, definition of survivin expression, and positive rate of survivin. If the HRs with 95\% CIs were not directly reported, we calculated them from Kaplan-Meier curves [22]. Each included study's quality was assessed by the Newcastle-Ottawa Scale (NOS). The study with $\geq 6$ points on NOS was evaluated as high quality.

\section{Statistics analysis}

Pooled estimates of OR and HR with 95\% CI were applied to evaluate the relationship of survivin expression with NPC clinical characteristics and prognosis, respectively. $\mathrm{Q}$ test and $\mathrm{I}^{2}$ statistic were used to conduct the heterogeneity test [23]. When $\mathrm{I}^{2}$ value $>50 \%$ or $\mathrm{P}$ value $<0.1$, which suggested significant heterogeneity, a random-effect model would be applied to calculate the estimate. Otherwise, a fixed-effect model would be used. Meta-regression was performed to evaluate the effects of the definition of survivin positivity and the level of survivin expression on the HR for OS. Meanwhile, Begg's test and Egger's test were used to calculate publication bias [24, 25]. In addition, the stability of the results was assessed by the sensitivity analysis [26]. All statistical analyses were performed by STATA 12.0 (STATA Corporation, College Station, TX, USA).

\section{Results}

\section{Literature characteristics and selection}

As shown in Figure 1, a total of 1794 potential studies were retrieved after duplicates were discarded. After reading the titles and abstracts, 1734 articles were excluded because they were conference abstracts, reviews, not human studies, case reports, or unrelated studies. After reading 60 full-text articles, a further 34 studies were excluded: 8 studies did not use immunohistochemical method for detection, 24 studies lacked sufficient data, and 2 studies showed overlapping data.

Consequently, a total of 26 studies [27-52] with 2278 patients were included in this meta-analysis. The main characteristics of the 26 eligible studies are summarized in Table 1. All the contained studies were 
designed retrospectively and were published between 2004 and 2019. Only one article was conducted in Canada, and the rest were performed in China. There were 8 studies presenting the relationship between survivin expression and overall survival (OS) in NPC patients. The NOS was applied to assess the quality assessment of all eligible studies, and the mean score of included studies was 6.6 (range 6-8).
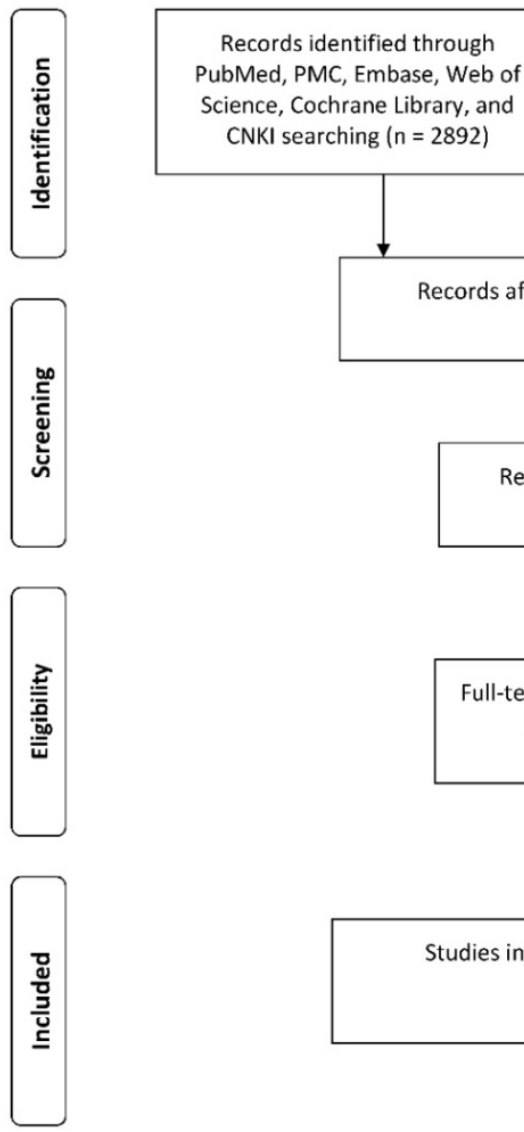

Additional records identified through other sources

CNKI searching $(n=2892)$

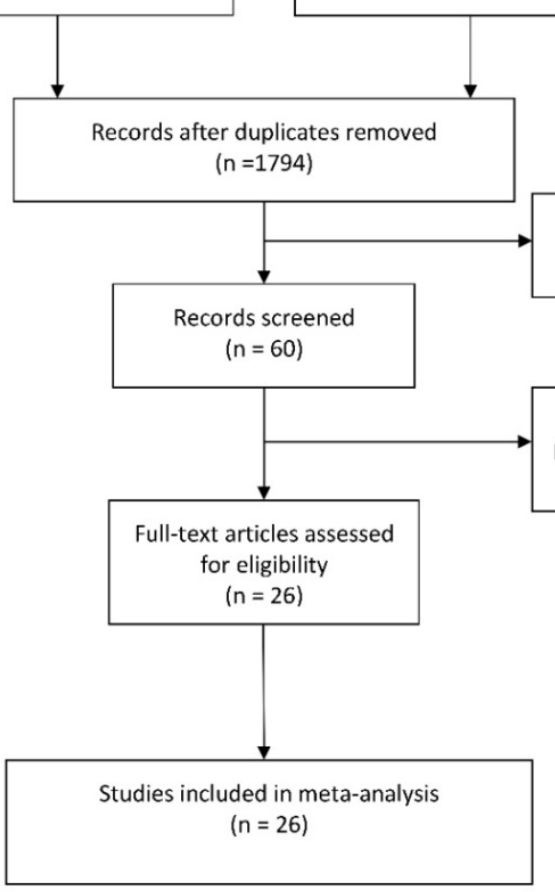

Records excluded $(n=1734)$

Full-text articles excluded: No reported sufficient data $(n=34)$

Figure 1. Flowchart presenting the steps of literature search and selection.

Study

ID

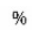

Weight

Jin 2019
Jiang 2010
Zhao 2008
Li 2008
Xiang 2006
Yip 2006
Xiang 2006
Jiang 2005
Overall (l-squared $=2.5 \%, p=0.410$ )

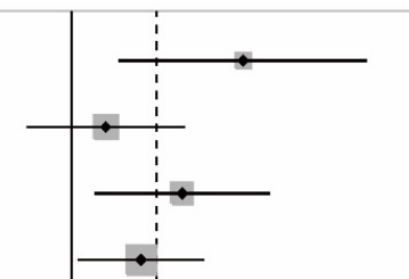

$4.48(1.51,13.30)$

$2.63(1.22,5.70)$

11.04

$1.83(1.06,3.18)$

$\begin{array}{ll}5.35(1.25,22.95) & 3.09\end{array}$

$2.04(0.98,4.24)$

$3.76(1.35,10.42) \quad 6.30$

$1.81(1.10,2.97) \quad 26.60$

$2.10(1.62,271)-100.00$

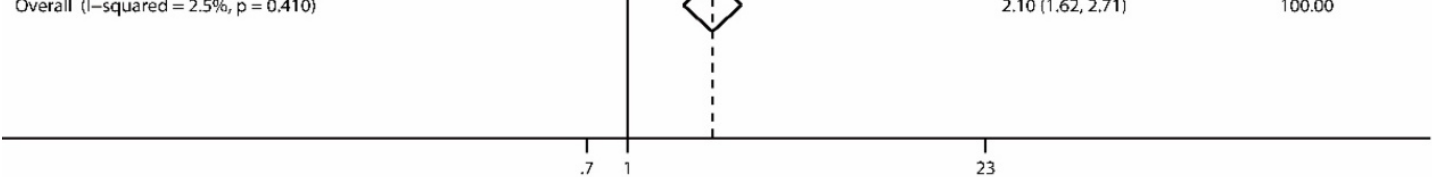

Figure 2. Forest plot depiction of survivin expression and hazard ratio (HR) for overall survival. 
Table 1. The main characteristics of included studies

\begin{tabular}{|c|c|c|c|c|c|c|c|c|c|c|}
\hline First author & Year & Country & No. of patients & $\begin{array}{l}\text { Median/Mean age } \\
\text { (range), years }\end{array}$ & Antibody source & $\begin{array}{l}\text { Definition of } \\
\text { positivity }\end{array}$ & Cut-off value & Survivin $+(\%)$ & $\begin{array}{l}\text { Study } \\
\text { design }\end{array}$ & NOS \\
\hline Lin [27] & 2012 & China & 72 & $47.8(14-78)$ & MXB & SS & Sum $\geq 3$ & 73.6 & $\mathrm{R}$ & 6 \\
\hline $\mathrm{Wu}[28]$ & 2014 & China & 106 & NM & NM & Per & $51 \%$ & NM & $\mathrm{R}$ & 7 \\
\hline $\mathrm{Xu}$ [29] & 2012 & China & 72 & $41(20-69)$ & MXB & Per & $26 \%$ & 72.2 & $\mathrm{R}$ & 6 \\
\hline Chen [30] & 2012 & China & 80 & $48(26-72)$ & Santa Cruz & SS & Pro $\geq 3$ & 61.3 & $\mathrm{R}$ & 8 \\
\hline Pan [31] & 2009 & China & 32 & $46(16-64)$ & ZSGB BIO & Per & $6 \%$ & 68.7 & $\mathrm{R}$ & 6 \\
\hline Jiang [32] & 2010 & China & 105 & $43(15-72)$ & $\mathrm{MXB}$ & Per & $6 \%$ & 58.0 & $\mathrm{R}$ & 7 \\
\hline Zou [33] & 2004 & China & 96 & $48(18-73)$ & MXB & Per & $6 \%$ & 75.0 & $\mathrm{R}$ & 6 \\
\hline Shu [34] & 2012 & China & 128 & $47.2(18-67)$ & NM & SS & Pro $\geq 1$ & 70.3 & $\mathrm{R}$ & 6 \\
\hline Qi [35] & 2004 & China & 33 & $46(28-69)$ & Santa Cruz & SS & Pro $\geq 1$ & 66.7 & $\mathrm{R}$ & 7 \\
\hline Chen [36] & 2008 & China & 50 & 45 & ZSGB BIO & Per & $10 \%$ & 88.0 & $\mathrm{R}$ & 6 \\
\hline Zhao [37] & 2008 & China & 68 & $53(22-74)$ & MXB & SS & Sum $\geq 2$ & 72.1 & $\mathrm{R}$ & 6 \\
\hline $\mathrm{Gu}[38]$ & 2008 & China & 68 & 49.8 & MXB & Per & $5 \%$ & 72.1 & $\mathrm{R}$ & 6 \\
\hline Huang [39] & 2006 & China & 230 & $44.6(7-83)$ & Santa Cruz & SS & Pro $\geq 3$ & 83.5 & $\mathrm{R}$ & 6 \\
\hline Huang [40] & 2009 & China & 57 & $51(21-78)$ & ZSGB BIO & SS & Pro $\geq 3$ & 68.4 & $\mathrm{R}$ & 7 \\
\hline Xiang [41] & 2006 & China & 68 & 45.6 & MXB & Per & $10 \%$ & 69.1 & $\mathrm{R}$ & 6 \\
\hline Zhou [42] & 2006 & China & 43 & $54.9(22-74)$ & MXB & SS & Sum $\geq 2$ & 76.7 & $\mathrm{R}$ & 7 \\
\hline Jiang [43] & 2005 & China & 115 & $45.8(18-65)$ & MXB & SS & $\operatorname{Pro} \geq 1$ & 68.7 & $\mathrm{R}$ & 6 \\
\hline Xiang [44] & 2006 & China & 92 & $45(18-71)$ & Santa Cruz & Per & $5 \%$ & 56.5 & $\mathrm{R}$ & 7 \\
\hline Yang [45] & 2015 & China & 45 & $(26-71)$ & NM & Per & $6 \%$ & 71.1 & $\mathrm{R}$ & 7 \\
\hline $\mathrm{Fu}[46]$ & 2014 & China & 72 & $41(20-69)$ & MXB & Per & $26 \%$ & 72.2 & $\mathrm{R}$ & 6 \\
\hline Li [47] & 2008 & China & 206 & NM & Santa Cruz & Per & $5 \%$ & 78.6 & $\mathrm{R}$ & 7 \\
\hline Xiang [48] & 2006 & China & 80 & NM & Santa Cruz & Per & $5 \%$ & 65.0 & $\mathrm{R}$ & 8 \\
\hline Yip [49] & 2006 & Canada & 80 & NM & Novocastra Lab & Per & $5 \%$ & 60.0 & $\mathrm{R}$ & 6 \\
\hline Jin [50] & 2019 & China & 164 & $45(24-70)$ & Santa Cruz & SS & Sum $\geq 3$ & 70.0 & $\mathrm{R}$ & 8 \\
\hline Chen [51] & 2006 & China & 83 & NM & Santa Cruz & Per & $5 \%$ & 66.2 & $\mathrm{R}$ & 6 \\
\hline $\mathrm{Hu}[52]$ & 2008 & China & 33 & $46(28-69)$ & Santa Cruz & SS & Pro $\geq 1$ & 66.7 & $\mathrm{R}$ & 7 \\
\hline
\end{tabular}

No., number; NM, not mentioned; SS, score system combining intensity and percentage; R, retrospective; Per, percentage of positive cells; Sum, the sum of intensity score and percentage score; Pro, the product of intensity score and percentage score; NOS, Newcastle-Ottawa Quality Assessment Scale.

\section{Survivin and survival}

The analysis of OS included 8 studies [32, 37, 43, 44, 47-50] with 910 patients. The heterogeneity test showed no significance $\left(\mathrm{I}^{2}=2.5 \%\right.$; $\left.\mathrm{P}=0.410\right)$; however, we found a significant association between survivin and OS. The expression of survivin was associated with a poor OS for NPC patients in a fixed-effects model $(\mathrm{HR}=2.10 ; 95 \% \mathrm{CI}=1.62-2.71 ; \mathrm{P}<0.001)$ (Figure 2).

\section{Survivin and clinical characteristics}

We also analyzed the relationship between survivin and NPC clinical features. For lymph node metastasis, 17 studies [30-38, 40-45, 47, 50] with 1450 patients were included. The result indicated a significant correlation between survivin expression and lymph node metastasis (OR=3.01; 95\% $\mathrm{CI}=2.31-3.91 ; \quad \mathrm{P}<0.001$ ) (Figure $3 \mathrm{~A})$. For local recurrence, 7 studies $[30,34,37,43,44,47,48]$ with 769 patients were included. We detected that survivin expression was associated with local recurrence $(\mathrm{OR}=2.40 ; 95 \% \mathrm{CI}=1.60-3.61, \mathrm{P}<0.001)$ (Figure 3B). For distant metastasis, 8 studies [30, 34, 37, 43-45, 47, 48] with 814 patients were included. The result also presented an obvious relevance between survivin expression and distant metastasis (OR=2.58; 95\%
$\mathrm{CI}=1.74-3.84, \mathrm{P}<0.001$ ) (Figure 3C). For clinical stage, 14 studies [30-32, 34, 37, 38, 40-43, 45, 50-52] with 1089 patients were included. Survivin expression was found to be prominently associated with more advanced clinical stage $(\mathrm{OR}=4.58 ; 95 \% \mathrm{CI}=2.81-7.47$, $\mathrm{P}<0.001$ ) (Figure 3D). However, we did not observe a significant correlation between survivin expression and radio-sensitivity ( $\mathrm{OR}=1.33 ; 95 \% \mathrm{CI}=0.25-7.17$, $\mathrm{P}=0.737) \quad$ (Figure 3E) or gender $(\mathrm{OR}=1.02$; 95\% $\mathrm{CI}=0.75-1.39, \mathrm{P}=0.887$ ) (Figure $3 \mathrm{~F}$ ).

\section{Sensitivity analysis, meta-regression analysis and publication bias}

In order to evaluate the variations, we conducted sensitivity analyses of OS. There were no obvious variations in the results, which shows their stability (Figure 4). Moreover, in meta-regression analysis, we did not identify the definition of survivin positivity $(\mathrm{P}=0.707)$ or the level of survivin expression $(\mathrm{P}=0.969)$ that was effect modifiers for influence of survivin on OS (Figure 5). Publication bias was detected in OS (Begg's test $\operatorname{Pr}>|z|=0.006$, Egger's test $P>|t|=0.011$ ). Accordingly, we used a trim and fill method to estimate the asymmetry in the funnel plot. The result had not materially altered (HR=1.94; 95\% $\mathrm{CI}=1.52-2.48 ; \mathrm{P}<0.001$ ) (Figure 6). 


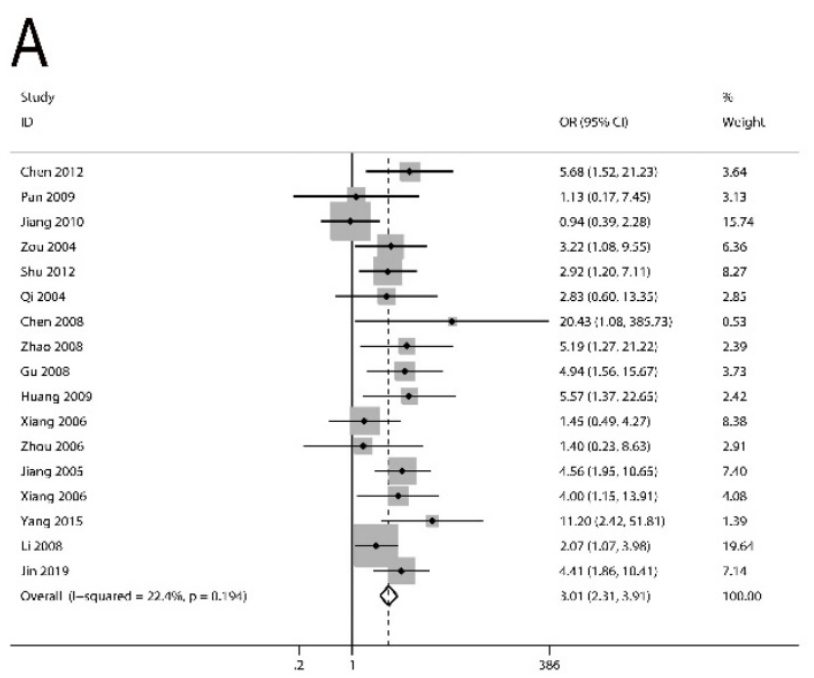

B
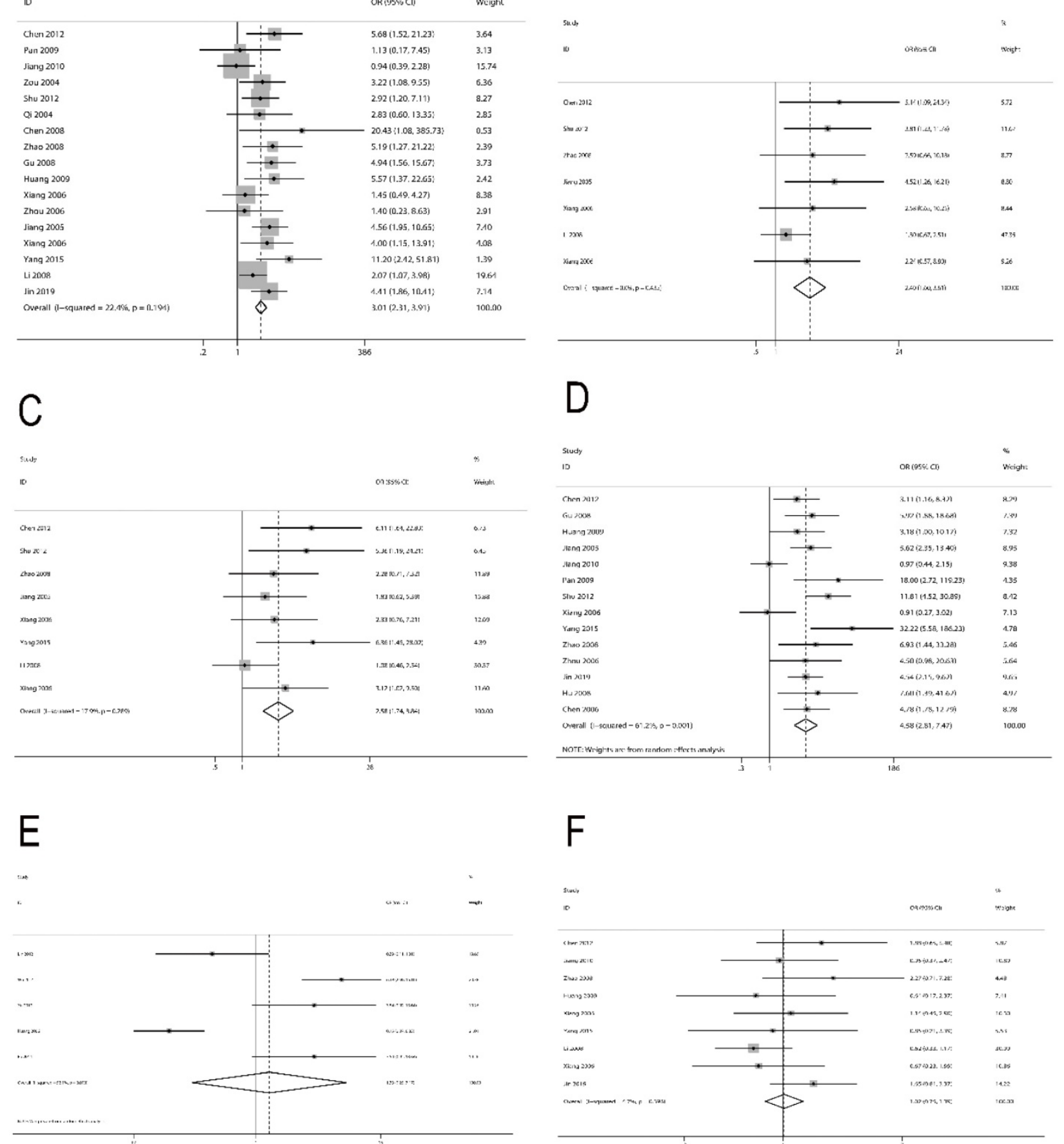

$\mathrm{F}$

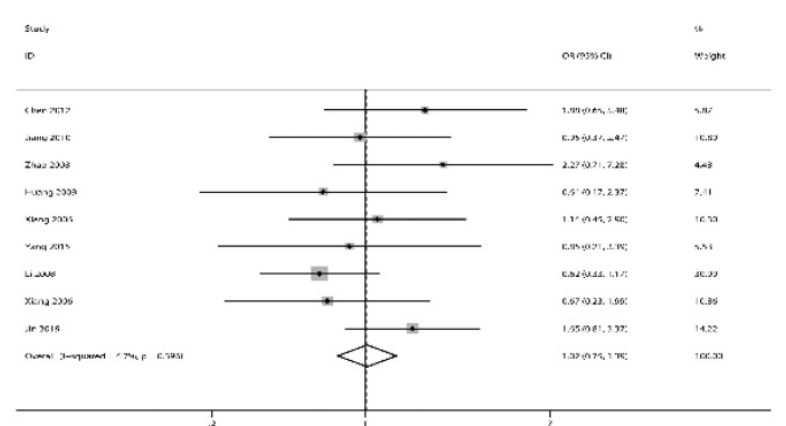

Figure 3. Forest plot depiction of survivin expression and odds ratio (OR) for clinical characteristics. A. Lymph node metastasis vs no lymph node metastasis. B. Local recurrence vs no local recurrence. C. Distant metastasis vs no distant metastasis. D. III/IV vs I/II. E. Radio-sensitivity vs radio-resistance. F. Male vs female.

\section{Discussion}

In the present meta-analysis, the pooled data showed promising prognostic value of survivin for NPC patients. We detected that survivin expression was related to poor OS in NPC. The risk of death in patients with survivin expression was 1.94 times higher than patients without survivin expression.
Furthermore, we also explored the relationship between survivin and clinical characteristics and found that survivin was related to a higher clinical stage, positive lymph node, local recurrence, and distant metastasis. Taken together, detection of survivin in NPC patients could help evaluate the malignant degree and predict prognosis. 


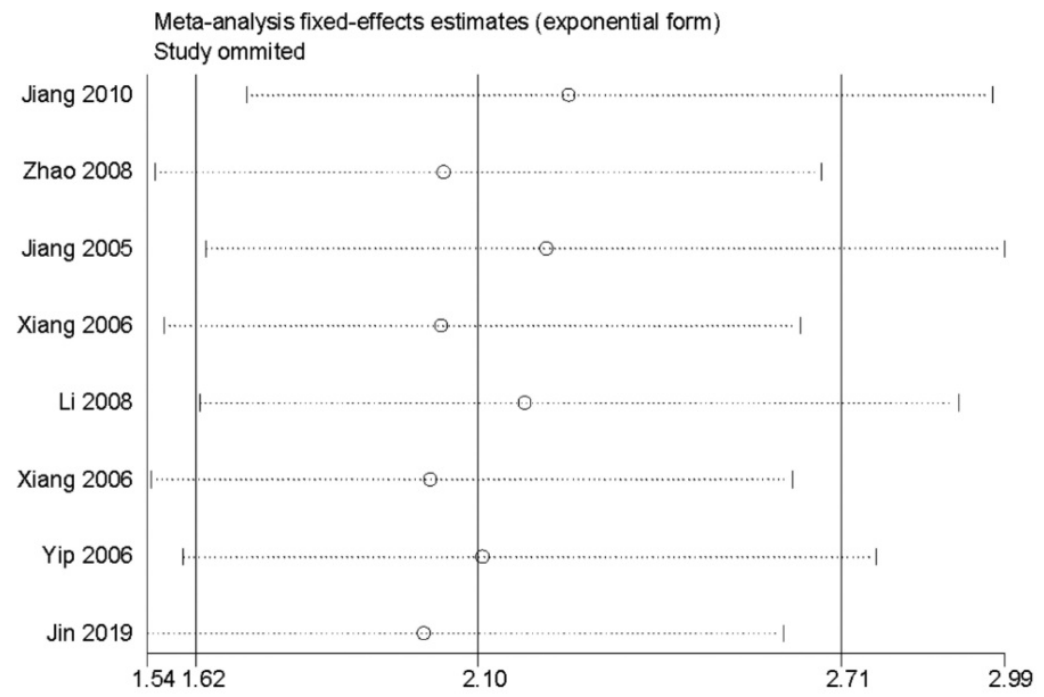

Figure 4. Sensitivity analysis for the association between survivin and overall survival.

A

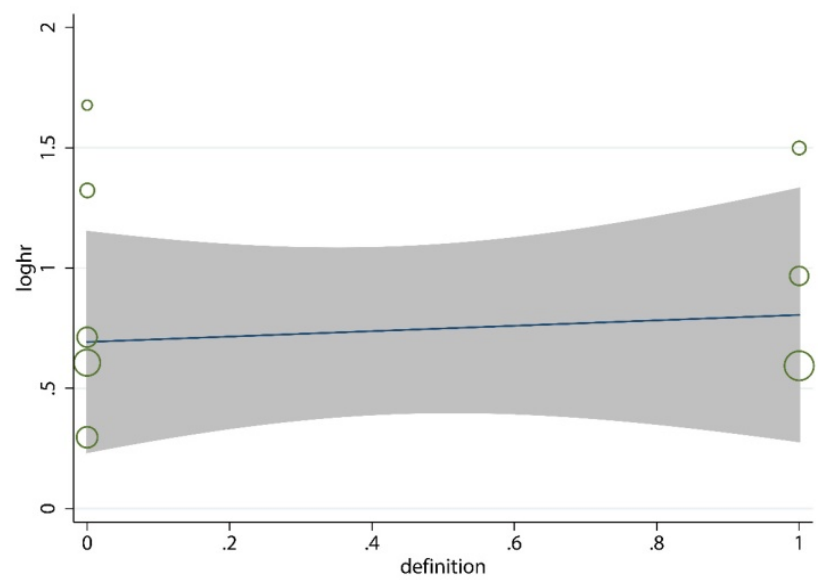

B

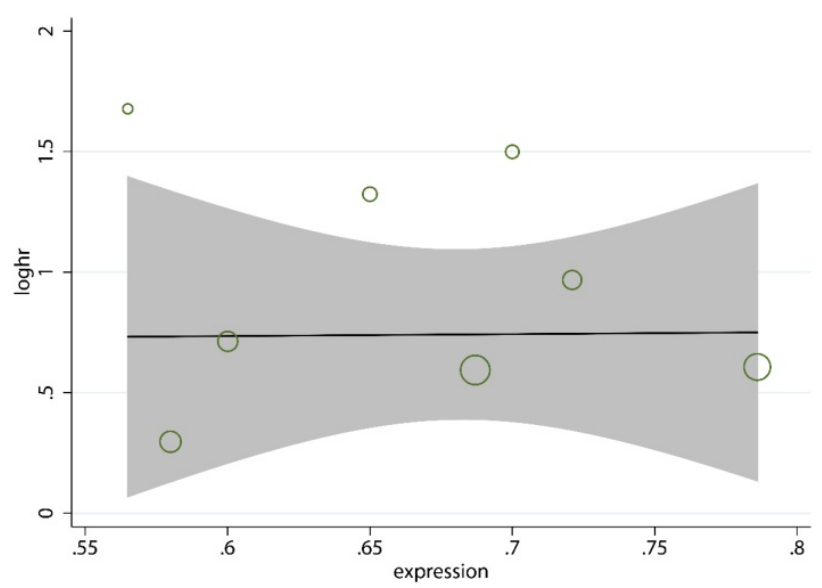

Figure 5. Meta-regression analysis for the association between the definition of survivin positivity (A), the level of survivin expression (B), and overall survival.

Our research was consistent with many previous studies exploring the prognostic role of survivin in other cancers. A meta-analysis of 11 studies demonstrated that survivin expression was significantly associated with poor $\mathrm{OS}(\mathrm{HR}=2.28 ; 95 \%$ $\mathrm{CI}=1.57-3.33$; $\mathrm{P}<0.001)$ and poor cancer-specific survival $(\mathrm{HR}=2.08 ; 95 \% \quad \mathrm{CI}=1.07-4.05 ; \mathrm{P}=0.032)$ in renal cell carcinoma [53]. Another meta-analysis also showed that higher survivin expression could predict worse $\mathrm{OS}(\mathrm{HR}=1.96$; 95\% $\mathrm{CI}=1.57-2.45 ; \mathrm{P}<0.001)$ in patients with glioma [54]. In non-small cell lung cancer, survivin expression was related to lymph node metastasis, TNM stage, and histological differentiation [55]. All these previous researches had indicated that survivin might serve as an important prognostic biomarker for cancer patients. In this meta-analysis, we showed the positive association of survivin with survival and clinical characteristics in NPC. However, we failed to detect any relationship between survivin and radio-sensitivity. This may due to the limited number of radio-sensitivity studies included.

The possible reason why survivin presents the prognostic value in NPC patients might be that survivin plays a key role in cell apoptosis. Survivin is composed of 142 amino acids and has a strong effect of inhibiting apoptosis [56]. Caspases play an important role in the process of apoptosis [57]. It has been shown that survivin blocks the process of apoptosis through directly inhibiting caspase activation [58]. The anti-apoptosis effect is closely related to the treatment resistance. It has been reported that anti-survivin siRNA enhances apoptosis and overcomes chemotherapy resistance in vitro [59] and in vivo [60]. In NPC, Shi et al. reported that the YM-155, which is a survivin inhibitor, induces apoptosis of NPC cells and inhibits tumor growth in the mouse model [61]. Apart from the inhibition of apoptosis, cell proliferation is also related to survivin. During the G2/M phase of the cell cycle, survivin is 

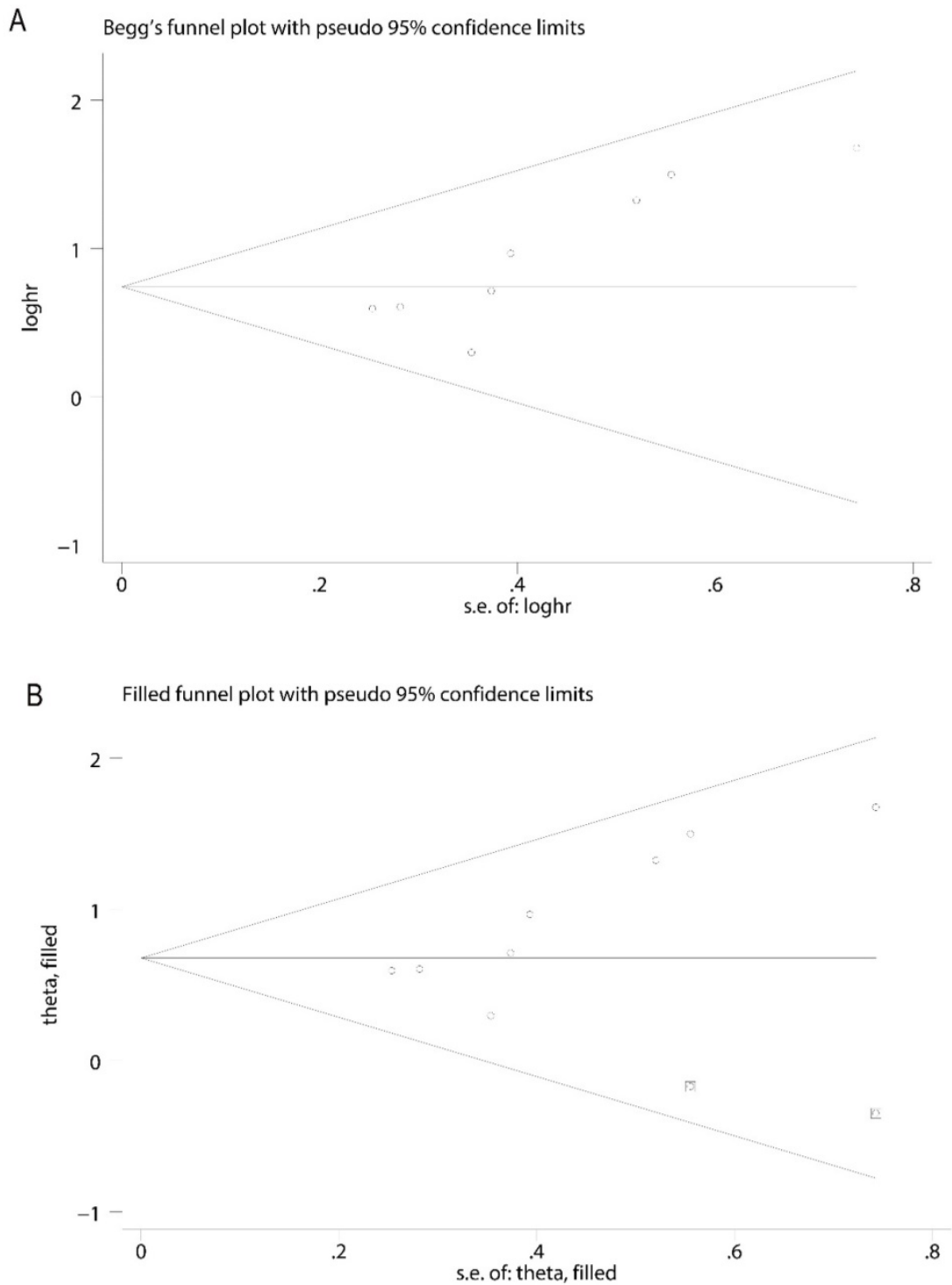

Figure 6. Funnel plot for publication bias analysis. A. The asymmetry of funnel plot was found, indicating possible publication bias. B. The trim and fill method was performed to rectify analysis, and no visible asymmetry was found in the funnel plot.

expressed and promotes cell division by binding to spindle tubulin $[62,63]$. Furthermore, it has also been reported that survivin plays an important role in tumor angiogenesis [64]. Taken together, it is believed that survivin could be an appropriate biomarker and a potential therapeutic target for prognosis prediction and precision therapy.

There were several limitations in this meta-analysis. First, a publication bias was detected in OS. This may due to the limited number of included studies $(n=8)$. The pooled data changed slighted but remained significant after the trim and fill method was conducted. Second, only English and Chinese literatures were included, selection bias and recall bias may exist in this meta-analysis. Third, because some studies did not directly report HRs, we extracted HRs from Kaplan-Meier curves. This may have influenced the accuracy of the results. Fourth, most of the included studies were published at 5 to 15 years ago, the last study was published in 2019. Taking into account these limitations, these results must be interpreted with caution when used in current clinical practice, and more studies are needed to verify our findings.

In conclusion, our meta-analysis demonstrated the prognostic value of survivin in patients with NPC. The expression of survivin can predict poor prognosis of NPC. Therefore, survivin might be served as a promising biomarker in survival prediction and targeted therapy. In the future, larger well-designed prospective studies are needed to verify our findings.

\section{Acknowledgements}

This work was supported in part by grants from the following sources: the Provincial Key Research and Development Program of Hunan Province 
(2018SK2123), the Key Laboratory of Translational Radiation Oncology, Hunan Province (2015TP1009), the Provincial Key Clinical Specialist Construction Projects of Hunan Province, and the Science and Technology Project of Changsha City (kq1701042, kq1901082).

\section{Competing Interests}

The authors have declared that no competing interest exists.

\section{References}

1. Chen YP, Chan ATC, Le QT, Blanchard P, Sun Y, Ma J. Nasopharyngeal carcinoma. Lancet. 2019; 394(10192): 64-80.

2. Torre LA, Bray F, Siegel RL, Ferlay J, Lortet-Tieulent J, Jemal A. Global cancer statistics, 2012. CA Cancer J Clin. 2015; 65(2): 87-108.

3. Chen W, Zheng R, Baade PD, Zhang S, Zeng H, Bray F, et al. Cancer statistics in China, 2015. CA Cancer J Clin. 2016; 66(2): 115-132.

4. Zhang Y, Chen L, Hu GQ, Zhang N, Zhu XD, Yang KY, et al. Gemcitabine and Cisplatin Induction Chemotherapy in Nasopharyngeal Carcinoma. N Engl J Med. 2019; 381(12): 1124-1135.

5. Lam WKJ, Chan JYK. Recent advances in the management of nasopharyngeal carcinoma. F1000Res. 2018; 7: F1000 Faculty Rev-1829.

6. Xu T, Zhu G, He X, Ying H, Hu C. A phase III randomized study comparing neoadjuvant chemotherapy with concurrent chemotherapy combined with radiotherapy for locoregionally advanced nasopharyngeal carcinoma: updated long-term survival outcomes. Ora Oncol. 2014; 50(2): 71-76.

7. Sun X, Su S, Chen C, Han F, Zhao C, Xiao W, et al. Long-term outcomes of intensity-modulated radiotherapy for 868 patients with nasopharyngeal carcinoma: an analysis of survival and treatment toxicities. Radiother Oncol. 2014; 110(3): 398-403.

8. Kitpanit S, Jittapiromsak N, Sriyook A, Prayongrat A, Kannarunimit D, Chakkabat $\mathrm{C}$, et al. Comparison between the seventh and eighth edition of the AJCC/UICC staging system for nasopharyngeal cancer integrated with pretreatment plasma Epstein-Barr virus DNA level in a non-Chinese population: secondary analysis from a prospective randomized trial. Jpn J Clin Oncol. 2019; 49(12): 1100-1113.

9. Pan J, Xu Y, Qiu S, Zong J, Guo Q, Zhang Y, et al. A comparison between the Chinese 2008 and the 7th edition AJCC staging systems for nasopharyngeal carcinoma. Am J Clin Oncol. 2015; 38(2): 189-196.

10. Tang LQ, Li CF, Li J, Chen WH, Chen QY, Yuan LX, et al. Establishment and Validation of Prognostic Nomograms for Endemic Nasopharyngeal Carcinoma. J Natl Cancer Inst. 2016; 108(1): djv291.

11. Ludwig JA, Weinstein JN. Biomarkers in cancer staging, prognosis and treatment selection. Nat Rev Cancer. 2005; 5(11): 845-856.

12. Lin JC, Wang WY, Chen KY, Wei YH, Liang WM, Jan JS, et al. Quantification of plasma Epstein-Barr virus DNA in patients with advanced nasopharyngeal carcinoma. N Engl J Med. 2004; 350(24): 2461-2470.

13. Li F, Aljahdali I, Ling X. Cancer therapeutics using survivin BIRC5 as a target: what can we do after over two decades of study? J Exp Clin Cancer Res. 2019; 38(1): 368

14. Wheatley SP, Altieri DC. Survivin at a glance. J Cell Sci. 2019; 132(7): jcs223826.

15. Roy K, Singh N, Kanwar RK, Kanwar JR. Survivin Modulators: An Updated Patent Review (2011-2015). Recent Pat Anticancer Drug Discov. 2016; 11(2): 152-169.

16. Fernandez JG, Rodriguez DA, Valenzuela M, Calderon C, Urzua U, Munroe D, et al. Survivin expression promotes VEGF-induced tumor angiogenesis via PI3K/Akt enhanced beta-catenin/Tcf-Lef dependent transcription. Mol Cancer. 2014; 13: 209.

17. Gunaldi M, Isiksacan N, Kocoglu H, Okuturlar Y, Gunaldi O, Topcu TO, et al. The value of serum survivin level in early diagnosis of cancer. J Cancer Res Ther. 2018; 14(3): 570-573.

18. Ma C, Lu B, Sun E. Clinicopathological and prognostic significance of survivin expression in renal cancer patients: a meta-analysis. Postgrad Med J. 2017; 93(1098): 186-192.

19. Troiano G, Guida A, Aquino G, Botti G, Losito NS, Papagerakis $S$, et al. Integrative Histologic and Bioinformatics Analysis of BIRC5/Survivin Expression in Oral Squamous Cell Carcinoma. Int J Mol Sci. 2018; 19(9): 2664.

20. Kapiris I, Nastos K, Karakatsanis A, Theodosopoulos T, Karandrea D, Kondi Pafiti A, et al. Survivin expression in hepatocellular carcinoma. Correlation with clinicopathological characteristics and overall survival. J BUON. 2019; 24(5): 1934-1942.

21. Liberati A, Altman DG, Tetzlaff J, Mulrow C, Gøtzsche PC, Ioannidis JP, et al. The PRISMA statement for reporting systematic reviews and meta-analyses of studies that evaluate health care interventions: explanation and elaboration. Journal of clinical epidemiology. 2009; 62(10): e1-34.
22. Tierney JF, Stewart LA, Ghersi D, Burdett S, Sydes MR. Practical methods for incorporating summary time-to-event data into meta-analysis. Trials. 2007; 8: 16.

23. Higgins JP, Thompson SG. Quantifying heterogeneity in a meta-analysis. Statistics in medicine. 2002; 21(11): 1539-1558.

24. Egger M, Davey Smith G, Schneider M, Minder C. Bias in meta-analysis detected by a simple, graphical test. BMJ (Clinical research ed). 1997; 315(7109): 629-634.

25. Begg CB, Mazumdar M. Operating characteristics of a rank correlation test for publication bias. Biometrics. 1994; 50(4): 1088-1101.

26. Higgins JP, Thompson SG, Deeks JJ, Altman DG. Measuring inconsistency in meta-analyses. BMJ (Clinical research ed). 2003; 327(7414): 557-560.

27. Lin J, Zhang C, Liu Z, An W, Li C, Li Q. The expression and the predicting value of COX-2 and survivin about radiotherapy sensitivity in nasopharyngeal carcinoma. China Journal of Modern Medicine. 2012; 22(22): 48-51.

28. Wu J. Correlation analysis of cyclin D1 and survivin expression and radiosensitivity in nasopharyngeal carcinoma. The Practical Journal of Cancer. 2014; 29(10): 1220-1222

29. Xu M, Lin S, Liang Z, Cai J, Fu S. Correlation between expression of cyclin D1 protein and survivin protein and radiosensitivity of nasopharyngeal carcinoma. Chinese Journal of Clinical Pathologist. 2012; 4(1): 11-14.

30. Chen J, Chen $\mathrm{Y}, \mathrm{Wu} \mathrm{Z}$, Chen $\mathrm{H}$. Expression of livin and smac in nasopharyngeal carcinoma and its clinical significance. The Practical Journal of Cancer. 2012; 27(1): 021-023.

31. Pan Y, Li J, Yin J, Chen X, Li X, Wang Z, et al. Expression of survivin, Bcl-2, $\mathrm{nm} 23-\mathrm{H} 1$ and the relationship with the pathological types and the clinical stage of nasopharyngeal carcinoma. Modern Oncology. 2009; 17(12): 2287-2290.

32. Jiang W, Zhang C, Luo Y, Huang Q, Zhu X. Study on correlation between nasopharyngeal carcinoma and expression of survivin protein. Jilin Medical Journal. 2010; 31(34): 6188-6191.

33. Zou J, Huang G, Chen Z, Chen H. Expression and clinical significance of survivin and PCNA in nasopharyngeal carcinoma. Journal of Chinese Physician. 2004; 6(2): 1636-1637.

34. Shu $\mathrm{Y}, \mathrm{Wu} \mathrm{M}$. The clinical studies on the expression of survivin protein in nasopharyngeal carcinoma. The Practical Journal of Cancer. 2012; 27(4): 362-365.

35. $\mathrm{Qi} \mathrm{W}, \mathrm{Hu} \mathrm{G}$. Expression and clinical significance of survivin protein in nasopharyngeal carcinoma. Chin J Otorhinolaryngol. 2004; 39(12): 759-760.

36. Chen Y. Correlation between expression of p53 and survivin and nasopharyngeal carcinoma. Shaanxi Medical Journal. 2008; 37(6): 693-695.

37. Zhao Y, Zhou L, He J, Wu Y. Expression of survivin and PCNA protein in nasopharyngeal carcinoma and their clinical significance. Mod Med J China. 2008; 10(9): 18-20.

38. Gu H. Expression of survivin and PTEN in nasopharyngeal carcinoma and its significance. Journal of Qingdao University (Medical Sciences). 2008; 44(04): 331-334.

39. Huang D, Tian Y, Qiu Y, Fan S, Li G. A study on PCNA and survivin as the molecule marks to predict tumor radiosensitivity of nasopharyngeal carcinoma. Journal of Tongji University (Medical Science). 2006; 27(5): 39-42.

40. Huang F, Kang R, Wu C. Expression of VEGF-C, nuclear factor-kappa B and survivin in nasopharyngeal carcinoma and their clinical implications. Journal of Shandong University (Health Sciences). 2009; 47(6): 83-87.

41. Xiang Q, He X, Tong W, Huang J, Lin Y, Lei X. Expression of survivin in nasopharyngeal carcinoma and its correlation with clinical stages and lymph node metastasis. Guangxi Medical Journal. 2006; 28(4): 478-480.

42. Zhou L, Zhou J, Wu Y. Relation between expression of COX-2 and survivin in NPC and their clinical significance. Suzhou University Journal of Medical Science. 2006; 26(1): 95-97.

43. Jiang W, Lu J, Wen J, Liao Y, Zhang J, Zhu H, et al. Clinical value of nm23-H1 and survivin protein expression in nasopharyngeal carcinoma. Chin J Radiat Oncol. 2005; 14(5): 383-387.

44. Xiang Y, Yao H, Guo X, Hong M, Cao S, Min H. Expression of survivin in nasopharyngeal carcinoma and its prognostic significance. Chin J Cancer Prev Treat. 2006; 13(2): 12-123

45. Yang N, Zhu L, Tan T, Hou C. Study of the relationship among expression of survivin and MRP and the drug resistance in human nasopharyngeal carcinoma. J Clin Otorhinolaryngol Head Neck Surg. 2015; 29(3): 235-239.

46. Fu SM, Xu MX, Lin SM, Liang Z, Cai JH. Association of cyclin D1 and survivin expression with sensitivity to radiotherapy in patients with nasopharyngeal carcinoma. Genet Mol Res. 2014; 13(2): 3502-3509.

47. Li YH, Hu CF, Shao Q, Huang MY, Hou JH, Xie D, et al. Elevated expressions of survivin and VEGF protein are strong independent predictors of survival in advanced nasopharyngeal carcinoma. J Transl Med. 2008; 6: 1.

48. Xiang Y, Yao H, Wang S, Hong M, He J, Cao S, et al. Prognostic value of Survivin and Livin in nasopharyngeal carcinoma. Laryngoscope. 2006; 116(1): 126-130.

49. Yip KW, Shi W, Pintilie M, Martin JD, Mocanu JD, Wong D, et al. Prognostic significance of the Epstein-Barr virus, p53, Bcl-2, and survivin in nasopharyngeal cancer. Clin Cancer Res. 2006; 12(19): 5726-5732.

50. Jin PY, Zheng ZH, Lu HJ, Yan J, Zheng GH, Zheng YL, et al. Roles of beta-catenin, TCF-4, and survivin in nasopharyngeal carcinoma: correlation with clinicopathological features and prognostic significance. Cancer Cell Int. 2019; 19: 48 
51. Chen J, Chen F. Expression of Epstein-Barr virus latent membrane protein 1 (LMP1) and survivin in nasopharyngeal carcinoma and their clinical significance. Canc Res Prev Treat. 2006; 33(10): 714-716.

52. Hu G, Qi W, Wang R. Expression and prognostic significance of survivin and bcl-2 in nasopharyngeal carcinoma. Acta Med Univ Sci Technol Huazhong. 2008; 37(1):109-116.

53. Pu Z, Wang Q, Xie H, Wang G, Hao H. Clinicalpathological and prognostic significance of survivin expression in renal cell carcinoma: a meta-analysis. Oncotarget. 2017; 8(12): 19825-19833.

54. Zhang S, Zhang $\mathrm{C}$, Song $\mathrm{Y}$, Zhang J, Xu J. Prognostic role of survivin in patients with glioma. Medicine (Baltimore). 2018; 97(17): e0571.

55. Duan L, Hu X, Jin Y, Liu R, You Q. Survivin protein expression is involved in the progression of non-small cell lung cancer in Asians: a meta-analysis. BMC Cancer. 2016; 16: 276.

56. Ambrosini G, Adida C, Altieri DC. A novel anti-apoptosis gene, survivin, expressed in cancer and lymphoma. Nat Med. 1997; 3(8): 917-921.

57. Van Opdenbosch N, Lamkanfi M. Caspases in Cell Death, Inflammation, and Disease. Immunity. 2019; 50(6): 1352-1364.

58. Lladser A, Sanhueza C, Kiessling R, Quest AF. Is survivin the potential Achilles' heel of cancer? Adv Cancer Res. 2011; 111: 1-37.

59. Chen X, Zhang Y, Tang C, Tian C, Sun Q, Su Z, et al. Co-delivery of paclitaxel and anti-survivin siRNA via redox-sensitive oligopeptide liposomes for the synergistic treatment of breast cancer and metastasis. Int J Pharm. 2017; 529(1-2): 102-115.

60. Salzano G, Navarro G, Trivedi MS, De Rosa G, Torchilin VP. Multifunctional Polymeric Micelles Co-loaded with Anti-Survivin siRNA and Paclitaxel Overcome Drug Resistance in an Animal Model of Ovarian Cancer. Mol Cancer Ther. 2015; 14(4): 1075-1084.

61. Shi J, Tan SY, Lee AZE, Zhang S, Sasidharan SL, Wong B, et al. Restoring apoptosis dysregulation using survivin inhibitor in nasopharyngeal cancer. Head Neck. 2020; 42(5): 913-923.

62. Jeyaprakash AA, Klein UR, Lindner D, Ebert J, Nigg EA, Conti E. Structure of a Survivin-Borealin-INCENP core complex reveals how chromosomal passengers travel together. Cell. 2007; 131(2): 271-285.

63. Altieri DC. New wirings in the survivin networks. Oncogene. 2008; 27(48): 6276-6284.

64. Ko D, Kim S. Cooperation between ZEB2 and Sp1 promotes cancer cell survival and angiogenesis during metastasis through induction of survivin and VEGF. Oncotarget. 2018; 9(1): 726-742. 